\title{
"QUANDO O FASCISMO SE TORNAVA CADA VEZ MAIS FORTE"*: DIREITO E EMANCIPAÇÃO EM FRANZ NEUMANN E BOAVENTURA DE SOUSA SANTOS
}

\section{Pedro Bigolin Neto}

Mestrando do Programa de Pós-Graduação em Direito da Universidade do Vale do Rio dos Sinos (UNISINOS), São Leopoldo, Rio Grande do Sul, Brasil. Membro do Núcleo de Direitos Humanos (NDH) da UNISINOS.

pbigolin@gmail.com

\section{José Rodrigo Rodriguez} Professor do Programa de Pós-Graduação em Direito da Universidade do Vale do Rio dos Sinos (UNISINOS), São Leopoldo, Rio Grande do Sul, Brasil; Pesquisador Permanente do Centro Brasileiro de Pesquisa e Planejamento (CEBRAP), Vila Mariana, São Paulo, Brasil. jrodrigorodriguez@gmailcom Recebido: janeiro 10, 2017 Aceito: março 16, 2017

\section{"When the fascists kept getting stronger": law and emancipation in Franz Neumann and Boaventura de Sousa Santos}

RESUMO

Este trabalho tem por objetivo trazer as contribuições teóricas de Franz Neumann e Boaventura de Sousa Santos no que tange ao direito e à emancipação. Primeiro são resgatados aspectos históricos das relações entre Estado, Direito e capitalismo. Em seguida são traçadas algumas características das perspectivas dos pensadores, que são posteriormente analisadas em conjunto. Com formações e vivências diversas, os dois autores contribuem para se pensar formas de emancipação social a partir do Direito, ambos polissêmicos. Constata-se semelhanças e divergências entre suas propostas, as últimas notadamente na visão a respeito do direito, que enriquecem o debate atual. Enquanto aquele trabalha primordialmente numa concepção estatal, este transita do local ao global. Ambos enxergam no capitalismo uma barreira para a emancipação e consideram 
imprescindível transformar os campos estatais, sociais e jurídicos nas páginas da história humana. As próximas, em branco, estão em disputa. A pesquisa é de cunho bibliográfico.

Palavas-chave: Direito, Emancipação, Globalização, Franz Neumann, Boaventura de Sousa Santos.

\begin{abstract}
This paper aims to bring theoretical contributions from Franz Neumann and Boaventura de Sousa Santos in relation to Law and emancipation. Firstly, historical aspects of relations between State, Law and capitalism are retrieved. Hereupon, some characteristics concerning the two thinkers' perspectives are outlined and then jointly analyzed. Having distinct formations and experiences, the two authors contribute to the thinking of forms of social emancipation through Law, both polissemic terms. Similarities and divergences between their propositions are evidenced, namely in their visions concerning Law, which enriches current debate. While Neumann works mainly with a view of the State, Santos transits from local to global. Both see in capitalism a hurdle to emancipation, and consider it's vital to transform state, social and juridical fields in the pages of human history. The next pages, in blank, are in dispute. The research is bibliographical.
\end{abstract}

Keywords: Law, Emancipation, Globalization, Franz Neumann, Boaventura de Sousa Santos.

\title{
1. INTRODUÇÃO
}

Eu, que nada mais amo Do que a insatisfação com o que se pode mudar Nada mais detesto Do que a insatisfação com o que não se pode mudar ${ }^{1}$

A tensão entre regulação e emancipação é um dos fatores que tem instigado a pesquisa acadêmica e social. Esta tensão não é um fenômeno característico do presente. Caiu em esquecimento com a ascensão do Estado de Direito, quando a emancipação integrou a regulação, mas aos poucos foi retomando espaço. Com a magnitude das transformações hoje vividas em diversas esferas, Ihe é outorgado um novo status, um certo papel de centralidade.

1 BRECHT, “Eu, que nada mais amo”, 2012, p. 82. 
No intuito de viabilizar uma compreensão acerca do tema, de analisar seu impacto na(s) sociedade(s) contemporânea(s), é imprescindível realizar um breve resgate histórico das relações entre Estado, Direito e capitalismo, já que é a partir desse conjunto relacional que a tensão referida vai ser estimulada a um ponto de saturação que não possui equivalente no passado. Disto trata o primeiro tópico do artigo, ao expor os três estágios de desenvolvimento do capitalismo, para o qual Estado e Direito desempenharam um papel fundamental. Mas tal relação não é linear e houve períodos em que o direito foi abandonado.

A temática de
mudança social
persiste até os
dias de hoje,
submetidos
ao jugo da
globalização
hegemônica
neoliberal,
que agrava as
desigualdades ao
mesmo tempo em
que as naturaliza.
O fatalismo,
fundamentado na
alienação, oculta
a possibilidade de
emancipação.

Um período que demonstra claramente este desdém para com o direito é o nazismo. Por ter vivido a supressão do Estado de Direito e das garantias fundamentais, o pensador Franz Neumann vai propor que sejam mantidas estruturas institucionais que garantam uma participação social e que, justamente a partir delas, se aumente a participação. A segunda seção vai explorar o autor, que toma como exemplo a influência exercida pelo proletariado ao ingressar no Parlamento e conseguir participar do processo legislativo, ocasionando a mudança das instituições dentro do seio estatal. Sua proposta é a de "Iutar pelo socialismo na imanência das instituições" ${ }^{\prime 2}$, isto é, de se ter no direito a via de alteração do modo de produção capitalista.

A temática de mudança social persiste até os dias de hoje, submetidos ao jugo da globalização hegemônica neoliberal, que agrava as desigualdades ao mesmo tempo em que as naturaliza. O fatalismo, fundamentado na alienação, oculta a possibilidade de emancipação ${ }^{3}$. A ocultação tem dimensões profundas, que podem ser detectadas no advento da ciência e do posterior etnocentrismo por ela justificado. Para se pensar fora desta circularidade, o terceiro tópico trata de Boaventura de Sousa Santos, que vai mostrar que outros saberes foram descartados, desqualificados e tiveram sua inexistência projetada. A articulação com diferentes conhecimentos de diferentes culturas que, por sua vez, possuem diversos projetos

\footnotetext{
RODRIGUEZ, 2009, p. 55.

A globalização hegemônica neoliberal se autoproclamou a única forma possível de existência humana após a queda do mudo de Berlim. Com esta ação, além de excluir todos os outros modos de vida que não se adequam aos postulados da racionalidade moderna, também criou uma atmosfera determinista, onde não há espaço para resistência ou mudança. SANTOS 2002 explica este processo a partir de uma crítica à racionalidade moderna.
} 
emancipatórios, pode afigurar-se numa forma muito interessante de construir uma contra-hegemonia, uma ecologia de saberes, que vai se servir dos instrumentos ofertados pela própria hegemonia - afinal, só a partir da modernidade é possível transcendê-la ${ }^{4}$. Por isso, o autor vai investir no desenvolvimento do princípio da comunidade obrado em Rousseau e na racionalidade estético-expressiva das artes em geral.

Por falar em arte, em função da crítica realizada ao modelo tradicional da racionalidade científica, como também levando-se em consideração a vivência de Neumann, optou-se por acrescer elementos poéticos neste trabalho, daí o convite para que Bertold Brecht visitasse essas páginas. $\mathrm{O}$ dramaturgo também contribui com fortes críticas partindo de outra racionalidade, de modo a se alternarem as formas de leitura deste escrito, num processo de complementaridade que é essencial na percepção da vida.

Expostas as visões específicas dos autores, propõe-se, na quarta subdivisão deste trabalho, uma análise das convergências e divergências entre os pensamentos, de modo dinâmico, sem pretender com isso uma resposta definitiva. Obviamente se tratam de teorias diferentes, de épocas diferentes, de autores influenciados por variadas escolas de pensamento, mas que partilham um mesmo ideal emancipatório no qual o direito está elencado como protagonista.

A ideia aqui compartilhada é a de demonstrar as contribuições de ambos os pensadores para compreender a situação atual e cogitar a situação futura. Embora Neumann já integre as páginas da história por estar no passado, Santos vive e escreve as do presente em simultâneo aos autores deste trabalho, de seus eventuais leitores e de todos os demais que neste momento habitam o planeta. Reiterando a proposta, portanto, há que se iniciar por revisitar as interações entre Estado, direito e capitalismo caso de deseje um adequado entendimento do presente.

\footnotetext{
4 SANTOS, 2000, p. 74.
} 


\section{ESTADO, DIREITO E CAPITALISMO}

A corrente impetuosa é chamada de violenta

Mas o leito de rio que a contém

Ninguém chama de violento.

A tempestade que faz dobrar as bétulas

É tida como violenta

E a tempestade que faz dobrar

Os dorsos dos operários na rua $a^{5}$ ?

O matrimônio entre Estado, Direito e capitalismo vai ser contraído com a ascensão da burguesia ao poder e representa a confirmação do projeto da modernidade, que prometeu criar uma sociedade livre, igual e solidária. Seu desdobramento é constituído por três estágios, a saber: capitalismo liberal, que vai até fins do século XIX, momento em que se instaura o capitalismo organizado, cujo declínio se esboça ao final da década de 1960 , sendo substituído pelo capitalismo desorganizado, que persiste atualmente ${ }^{6}$.

Orientado pelo capitalismo liberal, o Estado moderno vai se constituindo como órgão dentro do corpo internacional. Internamente, suas democracias vão servir aos interesses dominantes, que exercem o poder. Para tanto, o Estado vale-se do direito como ferramenta de institucionalização das relações de mercado e, no âmbito dos seres humanos, com o advento do positivismo, segue a cartilha de lei e da ordem? ${ }^{7}$.

O aparecimento do positivismo na epistemologia da ciência moderna e do positivismo jurídico no direito e na dogmática jurídica podem considerar-se, em ambos os casos, construções ideológicas destinadas a reduzir o progresso societal ao desenvolvimento capitalista, bem como a imunizar a racionalidade contra a contaminação de qualquer irracionalidade não capitalista, quer ela fosse Deus, a religião ou a tradição, a metafísica ou a ética, ou ainda as utopias ou os ideais emancipatórios ${ }^{8}$.

5 BRECHT, "Sobre a violência”, 2012, p. 140.

6 SANTOS, 2000, p. 139.

7 SANTOS, 2000, p. 140-141.

8 SANTOS, 2000, p. 141. 
A centralização

da produção normativa pelo Estado politizou o direito, que foi também tornado científico.

Este processo não somente transforma "o direito num instrumento eficaz da engenharia social oficial", como também torna $o$ Estado científico, técnico, imparcial.
A universalidade e abstração das leis estão centralizadas em um Estado-sujeito e um Estado-máquina. Enquanto sujeito impessoal, proporciona simultaneamente sua isenção quanto à participação nas relações de produção e sua confiança na busca do bem comum e, enquanto máquina, certifica-se "[d]a certeza e [d]a previsibilidade das suas operações e, acima de tudo, [d]a regulação eficaz das relações de mercado"

A centralização da produção normativa pelo Estado politizou o direito, que foi também tornado científico. Este processo não somente transforma "o direito num instrumento eficaz da engenharia social oficial", como também torna o Estado científico, técnico, imparcial ${ }^{10}$. Esta construção vai, aos poucos, revelar suas insuficiências na concretização das abstrações escritas, demandando uma revisão da postura estatal.

Deixado para que se regulasse sozinho, o mercado estruturou-se em oligopólios. Os direitos de participação política começaram a abrigar mais atores, levando à formação dos sindicatos, cujos integrantes, assim como partidos políticos do proletariado, acessaram aos poucos o cenário institucional liberal e operaram mudanças que transformaram a realidade social e a própria lógica jurídica ${ }^{11}$.

Desta forma, foi possível conciliar metas que eram excludentes entre si, posto que oriundas de diferentes camadas da população, alterando aquela visão burocratizada e impessoal para a de um espaço de negociação de interesses conflitantes. Para que isto fosse realizado, no entanto, foi necessário "reduzir os ideais de emancipação a proporções realistas", isto é, dentro dos limites proporcionados pelo capitalismo, deslocando a primazia abstrata do direito para situações concretas, contingentes, e amplificando a instrumentalidade jurídica. $O$ direito passa a intervir na economia, no intuito de minimizar as mazelas ocasionadas por sua ausência de regulação, de modo a moldar as políticas sociais, garantindo um caráter paternalista ao Estado-providência. Paradoxalmente, estando incrustado nas dinâmicas sociais, emerge a possibilidade de valer-se do direito estatal para fins não estatais ou até contra estatais ${ }^{12}$.

\footnotetext{
9 SANTOS, 2000, p. 142.

10 SANTOS, 2000, p. 143

11 SANTOS, 2000, p. 147-148.

12 SANTOS, 2000, p. 148-151.
} 
É inegável que a regulação tenha garantido melhora material nos estratos de menor renda outrora excluídos da esfera institucional. Tanto é que, a partir do ingresso da classe operária no Parlamento alemão, por exemplo, isto se tornou uma realidade que, em meio à unificação do capital industrial e do capital financeiro, que culminou em sua centralização e concentração, começou a preocupar as classes dominantes, de modo que fosse suprimido o direito pelo capitalismo monopolista e pelo nazismo ${ }^{13}$. A juridificação da vida, no entanto, precisa ser analisada com cautela:

A regulação jurídica põe em risco a identidade e a autenticidade das relações sociais pelo uso de categorias que perdem em abstração e passam a regular diretamente as diversas formas de vida, danificando seu funcionamento. Ainda, a proliferação da regulação de inúmeros objetos, a "inflação legislativa", faz com que o direito perca em organicidade e coerência interna, o que dificulta lidar com os conflitos sociais por meio de um conjunto articulado de premissas decisórias ${ }^{14}$.

Em função disso, a juridificação deve manter-se incompleta, isto é, não abranger a totalidade das relações sociais ${ }^{15}$. Este é um dos principais problemas da tensão dialética entre regulação e emancipação (soberania e liberdade) presente na modernidade, que será melhor abordada adiante.

Dando prosseguimento, é notório que desde as últimas quatro ou cinco décadas, o Estado intervencionista tem se desmantelado progressivamente, resultando em uma nova fase: o capitalismo desorganizado. Este adjetivo é ambíguo, uma vez que o que se está desorganizando são as instituições surgidas no período anterior. O capitalismo, a seu turno, nunca foi tão bem estruturado. Ousa-se falar, quiçá mais adequadamente, em um capitalismo desorganizante, pois ele tornou-se central no sistema mundial, passou a integrar as mais variadas órbitas da vida ${ }^{16}$.

\footnotetext{
RODRIGUEZ, 2009, p. 59-61.

RODRIGUEZ, 2009, p. XXVI.

RODRIGUEZ, 2009, p. 67.

16 SANTOS, 2000, p. 153-154.
} 
Na globalização ${ }^{17}$, ao mesmo tempo em que os mercados se desenvolvem com uma complexidade ímpar, formando teias de relações e agentes transnacionais, é igualmente visível a intensificação dos problemas acumulados pela história, principalmente a insatisfação das necessidades humanas na ordem material (para iniciar) e o surgimento de outros, como questões ambientais e relacionadas às transformações tecnológicas ${ }^{18}$, por exemplo, que não serão aqui abordados.

O Estado parece perder protagonismo na medida em que deixa de ser o único centro das práticas sociais, impactando suas políticas sociais ao procurar deixar de ser o responsável pelo bem-estar social. Consoante Boaventura:

O facto de, na maioria dos países, a degradação do desempenho social do Estado não Ihe ter diminuído significativamente o peso burocrático faz com que ao crescente enfraquecimento e ineficácia da administração pública venha juntar-se o crescente autoritarismo de um sem-número de burocracias desajustadas, cada uma exercendo o seu micro-despotismo sobre cidadãos cada vez mais impotentes e politicamente incapazes ${ }^{19}$.

Na seara internacional, torna-se visível que a perda de protagonismo se dá de formas distintas nos países do Norte e do Sul, já que estes estão cada vez mais condicionados pelos interesses de atores privados e do capital especulativo que, através dos organismos internacionais, cujo poder emana dos Estados do Norte, impõem medidas conforme o protocolo do Consenso de Washington. De fato, tais medidas, por vezes "apresentadas em combinações estranhas de liberalismo económico e de proteção dos direitos humanos", debilitam sobremaneira as já instáveis estruturas nacionais, que

17 O conceito de globalização é complexo e controvertido. Para a finalidade deste trabalho, será adotada a visão de Boaventura. Para ele "a globalização é o processo pelo qual determinada condição ou entidade local estende sua influência a todo o globo e, ao fazê-lo, desenvolve a capacidade de designar como local outra condição social ou entidade rival" SANTOS, 1997, p. 14. Ao contrário de outras posições, o autor reconhece o envolvimento de outras dimensões além da econômica, como a política, a social e a cultural. AVRITZER 2002 compartilha este conceito de globalização. Porém, afirma que com seu advento inclui-se um terceiro elemento na tensão entre regulação e emancipação: a não-regulação.

18 O avanço da técnica se dá em ritmo muito mais acelerado do que da previsibilidade das consequências de sua aplicação. Isto pode é perigoso para a humanidade pois, sem filtros para se barrar ações de repercussão incerta, corre-se o risco de comprometer a vida no planeta. SANTOS, 2000, p. 80-81; 111-113. Sobre a necessidade de se pensar o direito ambiental contrahegemonicamente, ver CARVALHO, 2015.

19 SANTOS, 2000, p. 155 
incorporam a "ideia da crise do Estado-Providência sem nunca terem usufruído verdadeiramente dele"20.

Por estar mais em evidência a queda do modelo anterior do que aquilo que virá a substituí-lo, a possibilidade de criação de novos horizontes é hoje algo a ser pensado. Há, inclusive, uma exaustão do imaginário reformista e revolucionário, o que gera a tentação de aceitar que o apocalipse é inevitável e que se deve regozijar na inércia até o dia da derrocada final. Isto pode ser explicado porque "estamos em um momento, em um período de transição, que é tardio demais para ser pós-revolucionário e prematuro demais para ser pré-revolucionário" ${ }^{21}$. Deste modo, apesar da existência desta tendência, há de se dizer que nos momentos de dificuldade existem aqueles que perseveram no intuito de transformar a realidade. Os dois autores podem se considerar incluídos nesta última parcela, razão pela qual são explorados. A análise começa, então, em Franz Neumann e sua forma direito.

\section{DIREITO E EMANCIPAÇÃO EM NEUMANN: A FORMA DIREITO}

A Europa é a fortaleza de Hitler Diz Goebbels a cada criança. Mas onde já se viu uma fortaleza Onde os inimigos estão não só do lado de fora Mas também do lado de dentro ${ }^{22}$ ?

Antes da apresentação conceitual propriamente, faz-se necessário expor a conjuntura histórica em que está inserido o autor. 0 período em que Franz Neumann desenvolve as ideias aqui mencionadas corresponde à ascensão do nazismo na Alemanha (capitalismo organizado, conforme a seção anterior), quando a fé depositada nas instituições jurídicas estava profundamente abalada. E é em função da abolição do Estado de Direito pelo nazismo que se tornará visível a importância de suas estruturas para a consolidação de um potencial emancipatório a partir do direito, "pois apenas nesse momen-

20 SANTOS, 2000, p. 155

21 SANTOS, 2007b, p. 101.

22 BRECHT, "A fortaleza Europa", 2012, p. 229. 
to a supressão do conflito social torna clara a função progressista dos direitos fundamentais" ${ }^{23}$. "A coruja de minerva só se levanta ao anoitecer: a supressão do Estado de Direito traz à luz seu conceito na forma da crítica e defesa do império do direito" 24 .

Este modelo de Estado surge quando a burguesia rompe com o modelo absolutista, ao se autoproclamar defensora dos interesses gerais da sociedade. Nesta senda, uma das características fundamentais é a substituição do exercício da vontade do soberano pela vontade geral $^{25}$, que passa a ser expressa por normas abstratas integrantes do direito formal. Referida construção ocorre no intuito de operacionalizar o mercado, cerne do capitalismo, e é justamente pela abstração carregada no seio normativo que se abre a possibilidade de implodir este modo de produção ${ }^{26}$. Nos dizeres de Neumann:

Desse modo, as pretensões da burguesia em ser uma nação encontram uma pretensão paralela por parte do proletariado constituindo a si mesmo como a nação. Do mesmo modo como a burguesia destituiu o domínio feudal e o absolutismo monárquico sob o slogan da "Representação da Vontade do Povo", também o proletário quer, por sua vez, representar a vontade do povo fundindo o Estado no proletariado, após este ter se tornado a nação. "As armas com as quais a burguesia derrotou o feudalismo estão agora voltadas contra a própria burguesia" ${ }^{27}$.

Portanto, o direito burguês, o império do direito em sua gramática essencial, a forma direito ${ }^{28}$, não só poderia como deveria ser mantido para que fosse percorrido o caminho traçado por Neumann rumo ao socialismo. Aqui se faz necessário um esclarecimento. Este trilhar

23 RODRIGUEZ, 2009, p. 59.

24 RODRIGUEZ, 2009, p. 10.

25 Conforme ensina Rousseau apud SANTOS, 2000, p. 131, uma das bases teóricas de Neumann neste aspecto: "A vontade geral não coincide necessariamente com a vontade de todos. O que generaliza a vontade não é o número de vozes, mas o interesse comum que as une". Importante esclarecer que Neumann não incorpora a ideia de vontade geral rousseauniana, apenas a forma do contrato. Sobre esse ponto, ver RODRIGUEZ 2009, p.102104 e PREUSS 2002, p. 100.

26 RODRIGUEZ, 2009, p. 70-71.

27 NEUMANN apud RODRIGUEZ, 2009, p. 79-80. No mesmo sentido, apontando a compatibilidade de uma agenda radical e o império do direito, ver SCHEUERMANN 1997, 2014, 2015. Em sentido contrário, OFFE 2003.

28 A forma direito, de acordo com RODRIGUEZ 2009, p. 72, diz respeito a "uma estrutura institucional que constrange o poder soberano a agir conforme a vontade da sociedade por meio de normas gerais e as instituições ligadas a elas (na forma clássica, os três poderes e seus órgãos), que instituem e garantem a separação entre soberania e liberdade, entre sociedade e Estado". Sobre este ponto, ver também PREUSS 2004. 
diz respeito a um contexto geo-histórico característico, dotado de instituições típicas, que tem por meta a emancipação da sociedade, sob as condições de um capitalismo monopolista (quando a proteção estatal dos mercados e a centralidade do direito estão em voga, não sendo a forma direito - ao contrário do que pensava em sua juventude - instrumento ${ }^{29}$ que venha "favorecer os interesses da classe operária" ${ }^{30}$. Obviamente, isto não elimina a priori todo o arcabouço teórico criado pelo autor, muito pelo contrário, como poderá ser visto adiante, uma vez que, globalmente falando, a situação dos mercados seja praticamente controlada por conglomerados transnacionais ${ }^{31}$. Alerta, todavia, para o equívoco que seria transportar automaticamente seus pressupostos à malha espaço-temporal presente.

Feita esta ressalva e retomada a exposição, tem-se que o autor concebe o direito como peça preciosa na "efetivação dos interesses da sociedade. Esta afirmação é surpreendente para um autor que se apresenta como um marxista", pois é oposta à ideia da esmagadora maioria dos autores do campo marxista que viam (e veem) no direito apenas uma forma de dominação e de alienação, um campo onde as batalhas nem deveriam ser travadas, posto que natimortas, invariavelmente ${ }^{32}$. Rodriguez sintetiza a escolha do filósofo alemão:

Neumann sustenta que a separação do Estado em duas esferas, soberania e liberdade em relação à soberania, acrescida da afirmação de que ele deve servir às necessidades e à vontade de todos os cidadãos, tem efeitos revolucionários. Este caráter revolucionário se alimenta da possibilidade de ampliação do espaço de participação política das forças sociais - consequentemente, da constante possibilidade de rediscussão das regras que presidem a relação entre os cidadãos - permitida pelas regras do Estado de Direito ${ }^{33}$.

A ampliação da participação política é efetivada na figura do proletariado, quando integra o parlamento, momento em que está apto a discutir a configuração da instituição que caracteriza o capitalismo:

\footnotetext{
29 A análise dos textos de Neumann em sua juventude não integra este artigo por questões metodológicas. Ver Capítulo 1 de RODRIGUEZ, 2009, que propõe, de forma inédita, esta periodização da obra de Neumann.

30 RODRIGUEZ, 2009, p. 84.

31 SCHEUERMANN, 2001, p. 508.

32 RODRIGUEZ, 2009, p. 79. No mesmo sentido, SCHEUERMANN 1997, 2014, 2015.

33 RODRIGUEZ, 2009, p. 79. Deste ponto em diante, a formulação é original de RODRGUEZ 2009
} 
a propriedade privada. A filosofia jusracionalista contratualista, após ser codificada e elevada ao status de lei, dotada da típica neutralidade científica ( $s i c)$, vê-se confrontada pelo mesmo instrumental e pela mesma linguagem de que dispôs para se consolidar no âmago das sociedades ocidentais e ocidentalizadas. Isto é, "no limite, a possibilidade de suprimir, via direito, a propriedade privada dos meios de produção" ${ }^{34}$.

O potencial de transformação social incubado neste raciocínio, cuja pretensão é a de satisfazer as promessas não cumpridas da modernidade, culmina em um dilema que, levando consigo uma astúcia salutar que colocaria em xeque a lógica dominante, bate nos portões do burgo e anuncia: "concretize a universalidade tão exaltada nas revoluções ou abra mão de seus frutos". Em outras palavras, o enigma reside em "satisfazer as reivindicações do proletariado e modificar a forma de distribuir as riquezas ou abandonar o governo das leis sobre os homens" ${ }^{\prime 35}$.

A democracia se vê cobrada a sair do papel e tornar-se viva, ocupar as ruas, transeunte em meio aos seres humanos de carne e osso (e sangue, muito sangue). Contudo, o resultado deixa a desejar (ao menos ao proletariado). Com a crescente e contínua atuação da parcela operária no sentido de formular suas postulações através do direito, tendo como destinatário o Estado, a burguesia se vê impelida a recusá-las, o que "choca-se frontalmente com a racionalidade da forma direito"36. A situação é assim narrada por Neumann:

O conceito de democracia é abandonado quando as massas, que despertaram recentemente e chegaram a uma autoconsciência política durante o período do industrialismo e da guerra mundial, exigiram essa democracia para si mesmas, e quando uma sociedade feudalizada pelo monopólio econômico é incapaz de satisfazer tais exigências ${ }^{37}$.

Ainda neste sentido, o que reforça o diagnóstico marxista de direito como alienação, o abandono se dá nas próprias estruturas do parlamento, o qual, de acordo com o pensador europeu, só opera normalmente enquanto representante dos interesses da burguesia:

34 RODRIGUEZ, 2009, p. 82.

35 RODRIGUEZ, 2009, p. 81.

36 RODRIGUEZ, 2009, p. 83.

37 NEUMANN apud RODRIGUEZ, 2009, p. 82. 
O Parlamento funciona normalmente, mas apenas enquanto as classes proprietárias o dominam. No exato momento em que a classe trabalhadora se emancipar, se tornar politicamente consciente, a burguesia abandonará a crença no império do direito instituído, e então recorrerá a um novo direito "natural" que não pode ser modificado pela legislação parlamentar e que consiste principalmente na ordem existente da propriedade - isso, contudo, somente durante um período de transição - ou ela abolirá o Parlamento juntamente com suas funções legislativas ${ }^{38}$.

Contudo, isto não vai abalar a convicção do autor quanto à imprescindibilidade das estruturas do Estado de Direito, tendo em vista que, por ser orientado por normas gerais, indeterminadas, o direito pode deixar de operar como ideologia e servir de linguagem para concretização dos interesses sociais ${ }^{39}$. 0 entreguerras alemão, no entanto, não tem nenhuma classe social que procure defender o Estado de Direito enquanto elemento chave para a regulação social, no sentido de "controlar juridicamente o espaço de indeterminação do direito materializado"40. A parcela que deu origem à essa estrutura vai deixar de lutar por sua manutenção e inclusive depositar esforços no sentido de eliminá-la, confirmando o diagnóstico elaborado ${ }^{41}$. Deste modo, com a ascensão de Hitler ao poder, o "regime nacional-socialista escancara a afinidade eletiva entre capitalismo e fascismo e sua incompatibilidade com a forma direito" ${ }^{\prime 2}$.

Ausente o pré-requisito da forma direito, assim sendo, torna-se impraticável a emancipação social dentro dos moldes jurídicos. Para que ocorra, não basta somente o preenchimento desta condição,

\footnotetext{
NEUMANN apud RODRIGUEZ, 2009, p. 75.

39 RODRIGUEZ, 2009, p. 79, 81.

40 RODRIGUEZ, 2009, p. 63, grifo do autor.

41 RODRIGUEZ, 2009, p. 64-65.

42 RODRIGUEZ, 2009, p. 76.
} 


A emancipação
tem como
condição o
exercício da
liberdade -
"capacidade de
autodeterminação
humana" -, que
pressupõe a
horizontalização
das relações
entre classes,
cujo impeditivo
é precisamente
a forma de
apropriação
dos meios de
produção.

A emancipação condição exercício da liberdade "capacidade de autodeterminação pressupõe a horizontalização das relações entre classes, sendo também necessária a existência de instituições ${ }^{43}$ que "afirmem a forma direito e, ao mesmo tempo, que apontem para além de si mesmas" ${ }^{\prime 4}$.

A propriedade privada, central para o capitalismo, também é central para o socialismo proposto, já que é através de mudanças operadas pelo parlamento (ou pelo judiciário, que não será aqui abordado), em seu complexo conjunto legal, que se transmuta um modo de produção em outro. Um exemplo disto reside na capacidade de desvincular a propriedade de um bem dos "poderes de retê-lo, controlá-lo e obter lucros, relação que, à primeira vista, aparece como natural"45. A hipótese de redistribuição com fulcro normativo desnaturaliza a premência de sua existência para o funcionamento da sociedade ${ }^{46}$.

A emancipação tem como condição o exercício da liberdade - "capacidade de autodeterminação humana" -, que pressupõe a horizontalização das relações entre classes, cujo impeditivo é precisamente a forma de apropriação dos meios de produção. Sua concretização plena acarreta a presença da liberdade em suas modalidades jurídica e sociológica: a primeira assegura o "espaço de liberdade em relação à soberania", enquanto a segunda amplifica o "espaço de escolha pelos indivíduos" ${ }^{47}$. Conforme os ensinamentos de Franz Neumann:

A liberdade, em um sentido filosófico, é a possibilidade real da auto-afirmação humana, o fim da alienação de si do homem. A realização desse "conceito concreto de liberdade" inclui as duas outras noções de liberdade ${ }^{48}$.

\footnotetext{
43 As instituições são assim definidas e exemplificadas pelo pensador germânico: "Entendemos por instituição o estabelecimento de uma relação de poder ou de cooperação de longo prazo com a finalidade de reprodução da vida social. A relação pode ser tanto entre pessoas ou entre bens ou mesmo entre pessoas e bens. Essa definição não tem qualquer implicação. Ela é uma descrição. [...] O conceito abrange todos os tipos de associações: instituições, fundações, a empresa, o estabelecimento, o cartel, o casamento. Ele abarca especialmente a principal instituição da sociedade burguesa: a propriedade privada dos meios de produção. A propriedade privada em si é um direito subjetivo e absoluto que concede direitos de defesa ao proprietário contra qualquer pessoa que perturbe a posse ou fruição do objeto da propriedade. Para além disso, a propriedade privada dos meios de produção é também uma instituição. Ela é pensada para o longo prazo, serve à produção e reprodução da vida social e dispõe as pessoas em um domínio de poder" NEUMANN, 2014, p. 29.

44 RODRIGUEZ, 2009, p. 86.

45 RODRIGUEZ, 2009, p. 92.

46 RODRIGUEZ, 2009, p. 75.

47 RODRIGUEZ, 2009, p. 87.

48 NEUMANN apud RODRIGUEZ, 2009, p. 127. Recentemente, AUBERT, 2015, mostrou a importância de Neumann para o debate sobre a liberdade no campo crítico.
} 
Neste sentido, a existência de direitos humanos positivados pelo Estado (direitos fundamentais), reguladores das relações sociais, contribui decisivamente na delimitação das "esferas da soberania e da liberdade em relação à soberania, tornando possível a legitimação democrática do Estado"49. O mínimo existencial destes direitos são as liberdades civis e políticas, que afastam da competência estatal soberana o poder de tomar decisões no âmbito privado. Podem ser considerados o núcleo imutável da forma direito. Dentre as normas, cumpre destacar a igualdade formal, a liberdade de associação e o direito de voto ${ }^{50}$.

Com isso, foi possível o ingresso do proletariado no parlamento, passando a integrar o sistema político e valendo-se do instrumental jurídico para realizar suas demandas e, em função desta "contaminação" do parlamento com o ingresso de outra classe social, a burguesia deixa de demonstrar a predileção de outrora por esse sistema. Ausentes essas garantias, abre-se margem à "invasão autoritária do Estado e de ações invasivas de outros particulares", levando à conclusão apontada por Rodriguez de que "não pode haver sociedade, não pode haver direito e, muito menos, a realização da liberdade"51.

Ao contrário do núcleo imutável da forma direito - os direitos civis e políticos - os direitos econômicos e sociais serão moldáveis de acordo com os interesses da sociedade. Portanto, o modo com que se dá a emancipação, a partir do direito burguês, é a mudança da função do direto. Como já visto, garantidas as liberdades proclamadas pelas normas gerais, o proletariado ganha acesso à construção do conteúdo inscrito nelas quando passa a habitar o parlamento, ocasionando o rompimento de um padrão aparentemente neutro que, no entanto, oculta profundas desigualdades. Fruto também desta luta e ascensão ao poder são os próprios direitos sociais, que levam visibilidade ao desequilíbrio da igualdade na distribuição de riqueza e atuam no sentido de compensar os excessos ${ }^{52}$.

\footnotetext{
49 RODRIGUEZ, 2009, p. 87.

50 RODRIGUEZ, 2009, p. 89.

51 RODRIGUEZ, 2009, p. 127. Importante ressaltar que a centralidade da entrada do proletariado no Parlamento na interpretação da obra de Neumann e a consequente relativização do direito de propriedade é uma contribuição original de RODRIGUEZ, 2009.

52 RODRIGUEZ, 2009, p. 75, 88-94.
} 
Com base neste breve panorama, é possível cogitar outras formas de apropriação de sentido das normas abertas com a finalidade de transformação social, bem como de inclusão de atores sociais e suas respectivas demandas no cenário jurídico. A forma direito permite que se preserve a tensão da relação entre Estado e sociedade, entre soberania e liberdade, mantendo-se aberta para o futuro e garantindo maior participação social e controle do poder soberano e também da regulação ${ }^{53}$. Evidentemente, ela é condição do processo, e não o processo em si, já que necessita de ações pontuais para que seja efetivada ${ }^{54}$.

Ainda dentro da relação entre direito e emancipação, se faz referência a uma proposta, desta vez contemporânea. Do próximo tópico se trata a exposição desta outra perspectiva, cujo autor é Boaventura de Sousa Santos.

\section{DIREITO E EMANCIPAÇÃO EM BOAVENTURA: A GLOBALIZAÇÃO CONTRA-HEGEMÔNICA}

A árvore que não dá frutos
Éxingada de estéril. Quem

Examina o solo?

O galho que quebra

Éxingado de podre, mas Não havia neve sobre ele ${ }^{55}$ ?

O paradigma inaugurado pela modernidade é um pensamento abissal ${ }^{56}$ e está fundado em dois pilares, quais sejam, regulação e emancipação. A regulação subdivide-se nos princípios de Estado, mercado e comunidade ${ }^{57}$; a emancipação, nos seguintes moldes de

\footnotetext{
53 RODRIGUEZ, 2009, p. 123, 152.

54 RODRIGUEZ, 2009, p. 148.

55 BRECHT, "Sobre a esterilidade", 2012, p. 141.

56 A linha abissal criada pelo pensamento moderno "[c]onsiste num sistema de distinções visíveis e invisíveis, sendo que as invisíveis fundamentam as visíveis. As distinções invisíveis são estabelecidas através de linhas radicais que dividem a realidade social em dois universos distintos: o universo 'deste lado da linha' e o universo 'do outro lado da linha' SANTOS, 2007a, p. 3.

57 De forma sucinta, SANTOS 2000, p. 50 descreve estas subdivisões: “O princípio do Estado consiste na obrigação política vertical entre cidadãos e Estado. O princípio do mercado consiste na obrigação política horizontal individualista e antagónica entre os parceiros de mercado. O princípio da comunidade consiste na obrigação política horizontal solidária entre membros da comunidade e entre associações".
} 
racionalidade: estético-expressiva, relativa às expressões de cunho artístico, cognitivo-instrumental, que corresponde aos saberes científicos e tecnológicos, e moral-prática, dentro da qual residem, originariamente, os conteúdos éticos e jurídicos ${ }^{58}$.

Estes deveriam ser desenvolvidos de forma harmoniosa e recíproca, submetidos à racionalidade, o que lhes conferiria maior previsibilidade. Suas contradições ficam evidentes, pois a materialização destas abstrações não progrediu homogeneamente, gerando excessos, "considerados desvios fortuitos", e défices, considerados "deficiências temporárias". Verificável é a falha deste projeto, uma vez que os acasos reincidiram reiteradamente, a ponto de fazer-se questionável sua aleatoriedade, bem como pela extensão da efemeridade das carências, que dura até o presente ${ }^{59}$.

A busca de soluções que este cenário fomenta deve se dar pelo reconhecimento das estruturas que não estejam perfeitas e acabadas em nossa época, ou seja, "só a partir da modernidade é possível transcender a modernidade" ${ }^{\prime 60}$. Neste sentido, Santos aponta para o princípio da comunidade e para a racionalidade estético-expressiva como as categorias modernas que devem ser mais bem trabalhadas. A escolha do autor quanto ao princípio da comunidade se baseia na ideia que este princípio "foi, nos últimos duzentos anos, o mais negligenciado", o que culminou praticamente em sua dissolução entre os outros dois. Ademais, ele "resistiu a ser totalmente cooptado pelo utopismo automático da ciência", o que o deixou em segundo plano. Afastado, não vem a incorporar a lógica dominante, o que possibilita seu diálogo com a emancipação61. Por se dar em uma relação horizontal de cidadão para cidadão, portanto extremamente participativa, a relação vertical para com o Estado é relegada a um plano inferior, o que implica no paradoxo de que "o exercício mais elevado da regulação é o exercício mais elevado da emancipação ${ }^{62}$. Ademais, de acordo com sua interpretação deste princípio, é possível ultrapassar a ideia de que a comunidade está necessariamente inscrita no Estado.

58 SANTOS, 2000, p. 50.

59 SANTOS, 2000, p. 51.

60 SANTOS, 2000, p. 74.

61 SANTOS, 2000, p. 75.

62 SANTOS, 2000, p. 131. 
Rousseau concebe o direito, simultaneamente, como um princípio ético incondicional e um eficaz instrumento 'positivo' de ordenação e transformação social. Esta pluralidade de dimensões do direito corresponde a uma pluralidade de dimensões do Estado. Por um lado, o Estado é todo-poderoso, porque é potenciado por um princípio absoluto de legitimidade: a vontade geral; mas, por outro lado, o Estado é indistinguível dos cidadãos, na medida em que eles têm o direito inalienável de decretar as leis pelas quais serão regulados. Assim, temos que concluir que a teoria política de Rousseau conduz, em última instância, à abolição ou ao desaparecimento do Estado" 63.

A racionalidade estético-expressiva, a seu turno, foi selecionada em função de sua maior resistência à cooptação "pela racionalidade cognitivo-instrumental e performativo-utilitária da ciência", que incidiu de forma mais acentuada na racionalidade moral-prática. Um dos motivos principais é que, geralmente, "a racionalidade estético-expressiva é, por 'natureza', tão permeável e inacabada como a própria obra de arte e, por isso, não pode ser encerrada na prisão flexível do automatismo técnico-científico"64.

No momento em que a produção do Direito tem como único agente o Estado, com o advento do Estado de Direito, "a tensão entre a regulação social e a emancipação social passou a ser um objeto mais da regulação jurídica" ${ }^{65}$. Outro fator é a cientifização deste direito, que ocorreu no intuito de amplificar sua operacionalidade "enquanto instrumento não científico de controlo social e de transformação social"66.

A intenção do pensador não é a de estabilizar regulação e emancipação, consoante a proposição da modernidade, mas sim "procurar um desequilíbrio dinâmico que penda para a emancipação, uma assimetria que sobreponha a emancipação à regulação" ${ }^{\prime 67}$. Por isso,

[...] nem o direito se resume ao direito estatal, nem os direitos se resumem aos direitos individuais. Isso não significa, contudo, que o direito estatal e os direitos individuais devam ser excluídos das práticas jurídicas cosmopolitas. Pelo contrário, eles podem ser usados, ainda que integrados em lutas mais vastas, que os retirem do molde hegemônico.

\footnotetext{
63 SANTOS, 2000, p. 131.

64 SANTOS, 2000, p. 75-76.

65 SANTOS, 2003, p. 4.

66 SANTOS, 2000, p. 165

67 SANTOS, 2000, p. 78.
} 
Esse molde, em essência, é a ideia de autonomia e a ideia de que os direitos são, ao mesmo tempo, meios e fins da prática social ${ }^{68}$.

Decorrência lógica é sua aceitação no que tange ao pluralismo jurídico. Todavia, o sociólogo adverte que, embora não hegemônicas, nem todas as formas de pluralismo são contra-hegemônicas, como é o caso da lex mercatoria, que contribui para a instauração do neoliberalismo e a subsequente exclusão social. A legalidade que vem de baixo, como direitos indígenas ${ }^{69}$ e direitos populares ${ }^{70}$, ao contrário, tende a contribuir para um maior grau de inclusão ou menor de exclusão ${ }^{71}$.

Falando em exclusão, uma nova onda conservadora está em pleno desenvolvimento, em conjunto com a derrocada dos Estados sociais, fazendo com que as alternativas institucionais restem severamente prejudicadas, senão inviabilizadas.
Falando em exclusão, uma nova onda conservadora está em pleno desenvolvimento, em conjunto com a derrocada dos Estados sociais, fazendo com que as alternativas institucionais restem severamente prejudicadas, senão inviabilizadas. Deste modo, o impedimento da emancipação social pelos moldes estatais também gerou a crise na regulação ${ }^{72}$, sendo imperioso reinventar a tensão outrora existente e repensar o direito para além dos moldes liberais e demo-socialistas, ao mesmo tempo em que combate o conservadorismo ${ }^{73}$. Este, por sua vez, "floresce sob o nome enganador de neoliberalismo. O neoliberalismo não é uma versão nova do liberalismo, mas antes uma versão velha do conservadorismo"74.

O fascismo social, "nova forma do estado de natureza"75, diferentemente daquele vivido por Neumann, não necessita abrir mão da democracia formal para estar vigente ${ }^{76}$, uma vez que parte da própria

\footnotetext{
68 SANTOS, 2003, p. 36.

69 Sobre a relação entre usos contra-hegemônicos do direito e povos indígenas, ver HAGINO e QUINTANS, 2015.

70 Envolvendo o direito à cidade de forma contra-hegemônica, ver MALDONADO, 2015.

71 SANTOS, 2003, p. 38-39. Para aprofundar esta perspectiva, no mesmo sentido, ver ARAGÓN, 2015 e MALDONADO 2015.

72 A leitura de Rodriguez sobre Neumann oferece outro diagnóstico, que não vê o impedimento total da emancipação dentro do Estado, como foi possível perceber no tópico anterior e será novamente abordado no próximo tópico.

73 SANTOS, 2003, p. 5-8.

74 SANTOS, 2003, p. 6.

75 SANTOS, 2007a, p. 17

76 Rodriguez tem utilizado o pensamento de Neumann como inspiração para criar categorias de análise que evidenciam práticas autoritárias ocultas por textos legais, alguns deles aprovados por meio dos procedimentos democráticos, ver RODRIGUEZ, 2016.
} 
sociedade e não do Estado, que permanece inerte ${ }^{77}$. Este é o caso, por exemplo, do "fascismo financeiro", viabilizado através do fluxo de capitais do mercado especulativo, capaz de desestabilizar economicamente - e politicamente - qualquer nação em poucos instantes. Para Boaventura é, com grandes indícios, "a forma mais pérfida de sociabilidade fascista"78.

Outra forma é o "apartheid social", verificável nas diferenças de tratamento - e neste caso o Estado é cúmplice - entre as populações integrantes de bairros "civilizados", com seus "castelos neofeudais", e dos bairros "selvagens", onde se despeja o direito penal do inimigo cotidianamente sobre os cidadãos" ${ }^{79}$. A crescente onda de "justiceiros" - tanto com quanto sem legitimidade institucional - no Brasil, apoiada por considerável parcela de seus habitantes, é outro fator que corrobora para o agravamento da situação, já que exercem uma espécie de vingança, verdadeiro calmante para aqueles que acreditam viver no "país da impunidade".

Bem se vê, portanto, que a situação não melhorará se as inclinações dominantes mantiverem seu curso inalterado. Contudo, o pensador europeu vai defender que o novo paradigma já está em gestação. A globalização não se dá somente em sua forma hegemônica - neoliberal -, mas também nas diversas lutas sociais contra as mazelas econômicas, políticas e sociais que dela decorrem, questionando a abrangência do interesse geral presente em seus discursos. É impossível ser geral enquanto promove a degradação ambiental e a exclusão social, que é fruto de disparidades em diversas relações de poder ${ }^{80}$.

A globalização contra-hegemónica é, por isso, um projecto plural, nisso residindo simultaneamente a sua força e a sua fraqueza. Tal pluralidade e diversidade não eliminam a possibilidade de comunicação, de compreensão mútua e de cooperação entre as diferentes lutas. De facto, o potencial e a viabilidade da globalização contra-hegemónica giram, exactamente, à volta dessa possibilidade. No entanto, tudo o que for conseguido graças à colaboração entre movimentos e organizações

\footnotetext{
77 Conforme esclarecimento do autor, "o fascismo de hoje não é um regime político, mas antes um regime social e civilizacional. Em vez de sacrificar a democracia às exigências do capitalismo, ele trivializa a democracia a ponto de se tornar desnecessário, ou sequer vantajoso, sacrificá-la para promover o capitalismo" SANTOS, 2003, p. 20-21.

78 SANTOS, 2003, p. 23-24.

79 SANTOS, 2003, p. 21.

80 SANTOS, 2003, p. 27.
} 
progressistas será menos o resultado de um ponto de partida comum do que de um comum ponto de chegada ${ }^{81}$.

Quando analisada esta pluralidade, estas redes, iniciativas, organizações e movimentos de resistência à globalização hegemônica, tem-se aquilo que o pensador vai chamar de "cosmopolitismo subalterno" 82 . Pode-se dizer que é uma faceta cultural e política da globalização contra-hegemônica, mas vista a partir de um enfoque mais amplo, global.

A globalização contra-hegemônica, nesta senda, consiste em num projeto político, social e cultural que tem por objetivo a reinvenção da emancipação social na transição paradigmática, partindo das lutas e resistências de movimentos sociais e da realidade dos países periferizados. Pressupõe, consequentemente, um desvelar de saberes ocultados pela modernidade. O conjunto da sociologia das ausências permite este movimento, o desencobrimento daquilo que foi produzido como não existente por não estar enquadrado nos rígidos preceitos modernos ${ }^{83}$. Deste modo, deve-se "transformar objectos impossíveis em possíveis e com base neles transformar as ausências em presenças" 84 .

Trata-se, em síntese, de: reconhecer a existência de outros saberes que não os científicos (o que não invalida a ciência, apenas Ihe coloca em pé de igualdade com relação a outros conhecimentos); perceber que o tempo não é linear, num nexo causal em que os países subdesenvolvidos estão atrasados com relação aos países desenvolvidos (atenção aos termos e aos critérios que orientam estas definições); desnaturalizar diferenças que produzem hierarquias (como gênero e etnia); dar-se conta de que o universal proposto pela globalização hegemônica é uma particularidade universalizada, havendo outras particularidades invisibilizadas em função disso; por fim, na visualização de outras formas de produção que não a capitalista, que cooperem ao invés de competir e que não tratem a natureza como mera fonte de recursos ${ }^{85}$.

81 SANTOS, 2003, p. 28.

82 SANTOS, 2007a, p. 20-21. Para uma compreensão breve da opção do autor pelo termo "cosmopolitismo", ver SANTOS 2007a, nota de rodapé 42 e SANTOS e GARAVITO-RODRÍGUEZ, 2005, p. 13-17.

83 SANTOS, 2002, p. 246-249.

84 SANTOS, 2002, p. 246

85 SANTOS, 2007a, p. 28-37. 
Aberto esse complexo leque, essa ecologia dos saberes ${ }^{86}$, deve-se buscar mecanismos de inteligibilidade e tradução que permitam a expressão destes diferentes saberes em articulação horizontal, de modo a se reforçarem enquanto projetos de emancipação sem, no entanto, destruir suas particularidades. Indaga o autor português acerca de quais ferramentas podem ser utilizadas para efetivação dessa proposta:

Estamos em um contexto no qual legalidade, direitos humanos e democracia são realmente instrumentos hegemônicos; portanto não vão conseguir por si mesmos a emancipação social; seu papel, ao contrário, é impedi-la. O central em nossa questão é saber se os instrumentos hegemônicos podem ter um uso contra-hegemônico. Como criar e fazer um uso contra-hegemônico da legalidade? Como fazer um uso contra-hegemônico dos direitos humanos e da democracia ${ }^{87}$ ?

Tendo enumerado estas categorias, que são mais um ponto de partida do que um rol taxativo, expandem-se os horizontes dos potenciais usos contra-hegemônicos das categorias hegemônicas. Dialogando diretamente com a sociologia das ausências, há a sociologia das emergências ${ }^{88}$. Com ela

[a]s características das lutas são ampliadas e desenvolvidas de modo a tornar visível e credível o potencial implícito ou escondido por detrás das aç̧ões contra-hegemônicas concretas. O alargamento simbólico gerado pela sociologia das emergências visa analisar as tendências ou possibilidades inscritas numa dada prática, experiência ou forma de conhecimento. Actua ao mesmo tempo sobre as possibilidades e sobre as capacidades. Identifica sinais, pistas, ou rastos de possibilidades futuras naquilo que existe. Uma abordagem tal permite-nos identificar qualidades e entidades emergentes numa altura e num contexto em que estas se arriscam a ser facilmente descartadas como sendo desprovidas de um devir, insignificantes, ou até retrógradas ${ }^{89}$.

\footnotetext{
${ }^{86}$ Assim estabelece o sociólogo lusitano: "A primeira lógica, a lógica da monocultura do saber e do rigor científicos, tem de ser questionada pela identificação de outros saberes e de outros critérios de rigor que operam credivelmente em contextos e práticas sociais declarados nãoexistentes pela razão metonímica. Essa credibilidade contextual deve ser considerada suficiente para que o saber em causa tenha legitimidade para participar de debates epistemológicos com outros saberes, nomeadamente com o saber científico" (SANTOS, 2002, p. 250).

87 SANTOS, 2007b, p. 68.

88 Conforme SANTOS, 2002, p. 254: "A sociologia das emergências consiste em substituir o vazio do futuro segundo o tempo linear (um vazio que tanto é tudo como é nada) por um futuro de possibilidades plurais e concretas, simultaneamente utópicas e realistas, que se vão construindo no presente através das actividades de cuidado".

89 SANTOS, 2003, p. 35.
} 
Utilizando-se deste instrumental na forma acima descrita, prossegue-se com a exposição deste raciocínio afirmando que a estratégia consiste em "lutar quando há condições dentro do Estado; trabalhar e lutar sempre fora do Estado; poder criar situações de poder dual ou dupla institucionalidade sempre" ${ }^{\prime 90}$. Com a influência do capitalismo neoliberal, que visa a privatização do Estado, o espaço público (enquanto estatal) de disputa tende a ser reduzido ${ }^{91}$. Isso faz com que a democracia, para ser efetiva, deva amplificar sua intensidade, contar com a participação ativa da população, não tendo como sinônimo a ideia de exercer sua cidadania por meio exclusivo do voto ${ }^{92}$. O modelo democrático neoliberal é uma democracia de baixa intensidade, dotada formalmente das instituições características de uma democracia, perfeitamente conciliável com o capitalismo pois, ao invés de reduzir as desigualdades sociais, as fomenta ${ }^{93}$.

Os direitos humanos, sob um viés multicultural que facilite o diálogo intercultural, podem servir igualmente à emancipação. Por sua teoria dominante estar marcada pelo eurocentrismo, pela epistemologia moderna, é necessário rever seus postulados iniciais e realizar um processo de tradução a partir do conceito de dignidade, presente em diversas culturas, ao contrário da noção de direitos humanos. Uma forma de diálogo intercultural proposta pelo autor é a da hermenêutica diatópica ${ }^{94}$, que vai trabalhar o significado dos termos dentro das culturas e em sua(s) zona(s) de contato ${ }^{95}$.

A legalidade cosmopolita ${ }^{96}$, isto é, a legalidade calcada na sociologia das emergências, vai buscar um caráter colaborativo entre direitos individuais e coletivos, ao contrário da visão maniqueísta que busca colocá-los em perpétua oposição ${ }^{97}$. Vale ressaltar que é um projeto

\footnotetext{
90 SANTOS, 2007b, p. 125.

91 SANTOS, 2007b, p. 66. Para uma visão não-estatal do espaço público, ver AVRITZER, 2002.

92 Sobre as críticas e proposições acerca da democracia, ver SANTOS, 2007b. No mesmo sentido, PEREIRA e CARVALHO, 2008 e MALDONADO, 2015.

93 SANTOS, 2007b, p. 90-92.

94 Segundo a definição de Boaventura SANTOS, 1997, p. 23: "A hermenêutica diatópica baseia-se na ideia de que os topoi [lugares comuns] de uma dada cultura, por mais fortes que sejam, são tão incompletos quanto a própria cultura a que pertencem. Tal incompletude não é visível do interior dessa cultura, uma vez que a aspiração à totalidade induz a que se tome a parte pelo todo. 0 objectivo da hermenêutica diatópica não é, porém, atingir a completude - um objectivo inatingível - mas, pelo contrário, ampliar ao máximo a consciência de incompletude mútua através de um diálogo que se desenrola, por assim dizer, com um pé numa cultura e outro, noutra.

95 SANTOS, 1997.

96 SANTOS; RODRÍGUEZ-GARAVITO, 2005, p.17-18.

97 SANTOS, 2003, p. 46.
} 
em aberto por ser formulado contemporaneamente, em conjunto às transformações sociais hodiernas, de modo a não somente respondê-las, a ser por elas influenciado, mas também influenciá-las.

Após a apresentação singela das principais ideias deste pensador quanto à emancipação, ousa-se retomar as ideias expostas anteriormente para, numa análise em conjunto, demonstrar algumas semeIhanças e distinções teóricas, sendo destinado na seção que segue seu espaço correspondente.

\section{CONVERGÊNCIAS, DIVERGÊNCIAS E UM FUTURO EM ABERTO}

As novas eras não começam de uma vez Meu avô já vivia no novo tempo

Meu neto viverá talvez ainda no velho. A nova carne é comida com os velhos garfos.

Os carros automotores não havia Nem os tanques

Os aeroplanos sobre nossos tetos não havia Nem os bombardeiros.

Das novas antenas vêm as velhas tolices. A sabedoria é transmitida de boca em boca ${ }^{98}$.

Os dois tópicos anteriores expõem, isolada e respectivamente, as contribuições teóricas de Franz Neumann e Boaventura de Sousa Santos a respeito de formas de operar a emancipação por meio do direito. No presente item, a proposição é de trazer uma reflexão de ambas nuances, de modo a tornar mais nítidas as convergências e divergências, sem com isso formular categorias em blocos monolíticos, nem tampouco eleger algum escolhido por uma razão qualquer, posto que isto seria completamente descabido.

Um dos pressupostos básicos da teoria crítica reside na realização do diagnóstico de tempo pelo pensador. Por se tratar de tempos distintos, seria necessária uma ambientação da teoria de Neumann aos dias de hoje, que não será realizada em sua totalidade, sendo enumeradas algumas interpretações de Rodriguez e Scheuermann.

98 BRECHT, "As novas eras", 2012, p. 294. 


\section{Talvez seja neste ponto, na valorização de uma certa "forma direito", mais do que em sua expressão sob o formato de "Estado nacional" ou de um "Pluralismo jurídico" que dê espaço para formas de vida comunitárias, é que a aproximação entre os dois autores se torne mais produtiva.}

O propósito deste tópico é colocar em paralelo as proposições sem ignorar a realidade histórica específica de cada um.

Interessante verificar que os diagnósticos realizados pelos autores aqui trabalhados possuem pontos em comum, mas que, por suas diferentes vivências, ocupam distintas abrangências. Enquanto o alemão enfatiza, a princípio, o Estado-nação, o português faz uma jornada transescalar, que vai do local ao global (e vice-versa), ocupando-se também do Estado, mas não apenas dele.

Apresentando de forma singela, ambos reparam: na ascensão do conservadorismo; na utilização (não só) do direito como instrumento de dominação; nas tentativas de reverter as inclusões sociais progressivas - progressistas - pelos setores dominantes; e, curiosamente, na manifestação destes sintomas como condição do desenvolvimento da consciência que alimenta a busca por alternativas, dentre elas a utilização do instrumental que compõe o núcleo do exercício da exploração e repressão.

Um vê, diante de si, a crescente onda nazista; o outro, a do fascismo social. Na visão de Neumann, a dominação exercida pelo direito tem como principais fatores a proliferação de normas gerais e do poder exclusivo, até um dado momento, da burguesia sobre a produção e interpretação normativa. Apenas a entrada da classe operária, então a principal força presente na sociedade civil, na disputa pela produção e pelo sentido do direito, é que é capaz de conferir a ele caráter emancipatório.

Por sua vez, Boaventura evidencia o crescimento do poder econômico sobre o Direito também no âmbito internacional e a descentralização da produção normativa pelos que detêm este poderio como formas de constranger a adoção das posturas neoliberais no seio estatal, além de ressaltar o caráter etnocêntrico que permeia o Direito. Cabe acrescentar que Scheuermann (2001, passim) chega às mesmas conclusões, referentes à tendência de repúdio ao formalismo jurídico na globalização em curso, a partir de uma leitura de Neumann transportada para nosso tempo.

Talvez seja neste ponto, na valorização de uma certa "forma direito", mais do que em sua expressão sob o formato de "Estado nacional" ou de um "Pluralismo jurídico" que dê espaço para formas de vida comunitárias, é que a aproximação entre os dois autores se torne mais 
produtiva. Afinal, de um lado, para Neumann, é a "forma direito" (que liga democracia ao formalismo jurídico) que faz com que o Estado-nação se degenere em uma forma de dominação unilateral, dotado de um direito que se torna apenas um arcanum dominationes.

De outro lado, Boaventura também está preocupado em distinguir formas emancipatórias e não emancipatórias de ordem normativa em uma perspectiva pluralista; ordens capazes de fornecer critérios para diferenciar direitos insurgentes de teor progressista de formas autoritárias como a lex mercatoria.

O ingresso do proletariado no Parlamento, as reivindicações feitas sob a forma de direitos e a posterior supressão do Estado de Direito alertaram para a imprescindibilidade da forma direito e, na atualidade, as atrocidades naturalizadas que culminaram na manifestação de diversos movimentos e setores em variadas partes do globo em nome de - na linguagem ocidental - direitos humanos e seus valores adjacentes denunciam, em uma oitava mais aguda, o persistente não cumprimento das promessas da modernidade, bem como a incapacidade de sua realização dentro da lógica moderna em vigência. Da mesma forma, talvez seja possível pensar na "forma direito", ou seja, em um conjunto de requisitos mínimos para qualquer normatividade que se pretenda jurídica, como critério que nos permita diferenciar ordens normativas totalitárias, ou seja, ordens normativas que deixem de expressar o desejo de autonomia de comunidades interessadas em ampliar seu horizonte de escolhas para serem veículo de visões de mundo violentas, discriminatórias, excludentes ou baseadas apenas em interesses econômicos.

Nesse sentido, talvez seja necessário propor alguns reparos ao dois autores, quem sabe, para pensar com eles, mas também para além deles. Afinal, a luta a partir da forma direito, no primeiro, assim como a proposta de globalização contra-hegemônica do segundo, embora tenham a finalidade emancipatória, não integram, numa primeira mirada, um mesmo projeto.

O sociólogo português confere ao direito um caráter instrumental99, algo semelhante ao que Neumann propunha em sua juventude,

99 O autor faz uso instrumental do direito por não concebê-lo de outra forma: "A redução do direito moderno ao direito estatal é apenas o processo pelo qual o direito renuncia à 'sua' subjectividade a favor do Estado. A instrumentalidade do direito estatal moderno é, portanto, uma condição original e nunca uma adulteração posterior de um primitivo ou original estado de coisas" SANTOS, 2000, p.162, nota de rodapé 48. 
quando era "tomado por ele como instrumento para a realização dos interesses" do proletariado ${ }^{100}$. Com a ascensão do nazismo e o abandono total do Estado de Direito, o pensador da Escola de Frankfurt vai rever sua postura para defender a "forma direito" enquanto tal, como expusemos logo acima.

Precisamente neste tópico parece residir a discordância entre os autores, posto que o teórico ibérico "perfilha uma visão não-essencialista do direito estatal e dos direitos" ${ }^{101}$. Contudo, o mesmo autor reconhece o desafio paradoxal que é lutar por direitos de inclusão dentro das estruturas próprias do direito ao revelar que a "disponibilidade para a manipulação, a contingência e a instabilidade procedentes de baixo são a maneira mais eficaz de contrariar a disponibilidade para a manipulação, a contingência, e a instabilidade procedentes de cima" ${ }^{102}$.

E é então que se percebe um outro ponto de contato entre as duas teorias, posto que o aumento da participação da sociedade na regulação social prevista na forma direito, assim como a transformação institucional que propõe para capacitar essa maior participação, vão ao encontro da globalização contra-hegemônica na medida em que há maior inclusão social e uma busca pela eliminação de opressões de ordem material na vida das pessoas. Para Boaventura, o direito estatal não é suficiente, ele é incapaz de dar conta, por assim dizer, da demanda crescente de liberdade e participação nascida da sociedade. Por isso mesmo, pode-se dizer que os dois autores veem no direito um potencial revolucionário: tanto a abolição da propriedade privada, para Neumann, quanto a criação de um paradigma não estatal para o direito são, nestes termos, uma metamorfose jurídica radical.

Mas é possível que as diferenças nas visões de um direito emancipatório nos dois autores se expliquem melhor pela distância histórica e, portanto, por seus diagnósticos do tempo. Neumann ainda vivia o momento inicial de centralização do poder estatal que, na Alemanha, ocorreu apenas no final do século XIX. Desenvolvendo seu pensamento na primeira metade do século XX, o autor não poderia sequer imaginar a dimensão da globalização vivenciada por

\footnotetext{
100 RODRIGUEZ, 2009, p. 15

101 SANTOS, 2003, p. 37

102 SANTOS, 2003, p. 37
} 
Boaventura. Tratava-se, para ele, de explorar o potencial emancipatório da forma estatal.

Assim se, por razões históricas, Neumann está preso à estatalidade, postulando sua democratização, Boaventura já aponta para a necessidade de democratização pela construção de um direito para além dos estados nacionais e para além do direito internacional clássico, este, igualmente marcado pela forma estatal. Mas, de qualquer maneira, ambos permanecem preocupados em reconstruir ou explodir o instituído como meio de democratização e emancipação.

Com efeito, Boaventura aposta na criação de novos espaços, não estatais, comunitários, posto que este princípio transcende a estatalidade, conforme já explanado, sem negar a importância da primeira estratégia, tanto que a reconhece como parte integrante do projeto cosmopolita, mas também concebe outras, nas quais deposita maior confiança, fruto de seus estudos culturais e - reitere-se - de estar inserido em outra época. Por essa razão, inclusive, que a demanda por igualdade, condutora e vencedora de significativas batalhas encampadas no terreno jurídico e político no passado, traz hoje consigo uma perigosa armadilha que será pelo sociólogo desarmada:

Vivemos hoje em sociedades obscenamente desiguais e, no entanto, a igualdade não se impõe como ideal emancipatório. A igualdade, entendida como equivalência entre iguais, acaba por excluir o que é diferente. Tudo o que é homogéneo à partida tende a transformar-se em violência exclusivista. Daí que as diferenças, por carregarem consigo visões alternativas de emancipação social, devam ser respeitadas ${ }^{103}$.

Por isso, também, sua aceitação quanto ao pluralismo jurídico que, como já mencionado, não é por si só garantia de integrar uma contra-hegemonia. A tendência de transnacionalização dos mercados traz consigo estratégias de tangenciar as normas produzidas pelo Estado, e até as próprias normas do Direito Internacional, pois autorregulação, soft laws e arbitragem criam uma barreira para a regulação social via direito estatal ${ }^{104}$. Tais acontecimentos maculam a capacidade de concretização de direitos sociais e constrangem a

103 SANTOS, 2003, p. 30

104 Sobre o fenômeno do pluralismo hegemônico a partir das contribuições de Boaventura, ver ARAGÓN, 2015, p. 277-284. 
possibilidade de participação nas decisões econômicas e políticas das camadas menos favorecidas e mais afetadas ${ }^{105}$. Em adendo, não havendo "qualquer forma de controle sobre as transações econômicas que atingem a sociedade para além das partes contratantes, pode-se dizer que estaríamos diante de um não-Estado de Direito"106, o que aponta, seguindo esta linha, para a instauração (manutenção?) de condições progressivamente desequilibradas.

Neste sentido, surge outra potencial incongruência na sincronização das diferentes emancipações analisadas. Diz-se potencial - e não necessária - pois, apesar da centralidade conferida ao direito estatal pelo pensamento exposto por Neumann, na crescente insurgência dos movimentos que demandam autorregulação, sua perspectiva, trazida aos dias atuais, abre margem para que "pode ser pensada como possibilidade de inventar novas instituições que realizem o controle social da regulação, em nível nacional e internacional”107. Ademais, dentro da formulação de Rodriguez, inexiste "risco de perda de autonomia do direito, se, em certas áreas, vigorar a auto-regulação (com a correspondente imunidade dos atos dos particulares garantida pelo poder soberano) e em outras a heterorregulação"108. Seguramente, o exemplo trazido acima não é uma delas.

Exatamente pela tendência de fuga do direito por parte dos conglomerados transnacionais Boaventura constata que é inconcebível pretender a democratização do Estado sem que a democratização não-estatal também ocorra. Para o autor, somente "a convergência dos dois processos de democratização garantirá a reconstituição da esfera pública" ${ }^{109}$. Referida afirmação é preciosíssima, pois clarifica o viés inclusivo de uma teoria em construção, o que mantém a possibilidade de surgimento de novas formas de combate ao cenário que se instaura e agrava.

Com isso, como já ficou em evidência, não se pretende, peremptoriamente, afirmar ou negar a compatibilidade entre ambos. Uma resposta desta magnitude é bem propícia de afigurar-se um reducionismo, no mínimo carente de compromisso com a pesquisa acadêmica. A busca

105 SCHEUERMANN, 2001, p. 513-514.

106 RODRIGUEZ, 2009, p. 12

107 RODRIGUEZ, 2009, p. 131

108 RODRIGUEZ, 2009, p. 153, grifo nosso.

109 SANTOS, 2003, p. 65-66. 


\section{Quanto a este ponto, a análise conjunta dos dois autores nos coloca diante do desafio de pensar o que poderia ser uma "forma direito" capaz de garantir o caráter democrático tanto do direito estatal quando de direitos não estatais, criados por comunidades descentralizadas e plurais.}

se dá no sentido de demonstrar que há semelhanças e também diferenças, num entrelaçamento que não pode ser analisado pelo viés dicotômico e monocromático da modernidade. Trata-se de reconhecer a multiplicidade complexa intrínseca à vida que, na luta pela emancipação humana, também é manifesta, já que o termo é polissêmico e necessita ser contextualizado nas realidades que pretende alterar ${ }^{110}$.

De igual sorte, reitera-se, o pensamento formulado por Neumann não pode ser aplicado automaticamente em nossa realidade, pois não corresponde à ela. Ainda assim, não são mutuamente excludentes $a$ priori, como se pôde perceber a partir das releituras de Rodriguez e Scheuermann. Mantendo-se esta atitude, abrem-se caminhos a intersecções que merecem ser mais bem exploradas no intuito de se concretizar um ideal compartilhado (não só) pelos autores.

Quanto a este ponto, a análise conjunta dos dois autores nos coloca diante do desafio de pensar o que poderia ser uma "forma direito" capaz de garantir o caráter democrático tanto do direito estatal quando de direitos não estatais, criados por comunidades descentralizadas e plurais. Nesse sentido, abstraindo o estado do conceito de direito de Neumann e perseguindo na obra de Boaventura critérios para diferenciar ordens plurais emancipatórias e regressivas seja possível buscar elementos para construir tanto uma visão de Estado quanto uma visão de Pluralismo democrática e emancipatória.

\section{CONSIDERAÇÕES FINAIS}

Quanto mais numerosos os que sofrem, mais naturais parecem seus sofrimentos, portanto. Quem deseja impedir que se molhem os peixes do mar?

E os sofredores mesmos partilham dessa dureza contra si e deixam que Ihes falte bondade entre si.

É terrivel que o homem se resigne tão facilmente com o existente, não só com as dores alheias, mas também com as suas próprias. Todos os que meditaram sobre o mau estado das coisas recusam-se a apelar à compaixão de uns por outros. Mas a compaixão dos oprimidos pelos oprimidos é indispensável. Ela é a esperança do mundo ${ }^{111}$.

\footnotetext{
110 SANTOS, 2003, p. 42.

111 BRECHT, "A esperança do mundo", 2012, p. 222.
} 
A tensão entre regulação e emancipação se faz presente nos dias atuais de forma muito intensa. A partir das leituras realizadas, foi possível visualizar a cooptação da emancipação por parte da regulação instaurada na modernidade. O papel desempenhado pelo direito, cooptado a seu turno pelo Estado, foi imprescindível. Baseado em premissas que Ihe outorgavam status científico, universalizou a particularidade burguesa.

Aceito como universal, o direito foi gradualmente aceitando novos membros na dinâmica estatal. Na Alemanha, o proletariado passa então a formular suas reivindicações em linguagem jurídica, causando incômodo nas classes dominantes que, para manterem ao máximo seus privilégios, optaram por abandonar o Estado de Direito, inaugurando uma das fases mais desumanas da humanidade.

Também neste momento, Franz Neumann vai se dar conta do quão precioso é o império do direito, formado pelas liberdades civis e políticas e pelas instituições que garantam seu adequado funcionamento. Tais dispositivos proporcionam o aumento do controle da elaboração da regulação social por parte da vontade geral, distinta da vontade da maioria. Os direitos sociais, a seu turno, teriam seu conteúdo preenchido pelas demandas operárias, transformando a função do direito burguês em seu revés: a extinção da propriedade privada. Abriu-se caminho para, a partir do próprio direito, eliminar uma das principais razões da existência do direito moderno.

Esta teoria não foi aproveitada no momento de sua formulação, tendo aguardado muito tempo para que fosse lida e debatida outra vez. A sociedade, neste lapso temporal, já passou por processos que não permitem uma mecânica transposição daquilo que fora dito outrora. Num momento do mundo em que o capitalismo, orientado pelas medidas inescrupulosas do neoliberalismo, constitui o núcleo da vida humana e se internacionaliza, criando redes de relações que passam longe do conhecimento e poder de intervenção social, torna-se uma necessidade de primeira ordem refletir. Refletir para libertar-se das amarras invisíveis, já que naturalizadas, de uma hegemonia nada discreta.

Aquela mesma universalidade que garantiu aos operários o acesso ao mundo jurídico e político é a que pode hoje ser utilizada para os inúmeros movimentos insurgentes, portadores de lógicas variadas 
em função das diferentes culturas em que estão inseridos. Saliente-se que, na leitura dos que a escreveram originariamente, tal possibilidade se afiguraria nula. Não somente nula, mas negativa: uma verdadeira afronta. Atualmente, há quem ainda deseje lê-la como se estivesse na Europa do século XIX. No entanto, situam-se no Brasil - que não gozava destas prerrogativas naquela época - e no século XXI, para infelicidade deles (ou daqueles com quem coexistem).

O crescimento de uma nova onda conversadora, fascista em uma ampla gama de incidências, realiza um esforço hercúleo para ignorar a história. Ciente disso, Boaventura de Sousa Santos vai propor uma outra mirada do projeto moderno, repleto de promessas não realizadas. A globalização possui outras facetas - contra-hegemônicas - sobre as quais se apoiam os que guardam irresignação com a situação econômica, política e social. As ferramentas que dispõem os detentores do poder são objetos de disputa, e um uso não ortodoxo delas pode viabilizar um outro projeto de vida, em constante autocrítica, que alimente o diálogo intercultural para concretizar a ideia de uma sociedade plural e horizontal.

Os pensadores não podem ser enquadrados em uma mesma categoria, não ao menos sem adaptar Neumann aos dias de hoje. Todavia isto não impede que de alguma forma possam haver contribuições mútuas. Afinal, enxergam um mesmo obstáculo e têm uma mesma finalidade, quais sejam: o capitalismo e a emancipação, respectivamente. Não há para isto uma resposta definitiva, categórica. Por ora, cabe a constatação de que suas linhas de raciocínio se entrecruzam, sem necessariamente se entrelaçarem.

As contribuições críticas de Brecht, muitas das quais poderiam ter sua autoria confundida com algum autor contemporâneo, também agregam valor à análise na medida em que as expõe partindo de outra racionalidade: a estético-expressiva. Esta é a mesma racionalidade que o sociólogo português trabalha e pretende desenvolver para ultrapassar as limitações que o cientificismo impôs.

As mudanças características desta fase de transição não vão ter respostas encontradas em manuais escritos pelos antigos, tampouco haverão soluções simples para os complexos problemas vividos. Uma coisa, contudo, parece certa: só a partir da modernidade será possível transcendê-la. 


\section{REFERÊNCIAS}

ARAGÓN, Orlando A. A disputa pela diversidade jurídica nos tempos da globalização neoliberal. A propósito, poderá o direito ser emancipatório? Revista Direito e Práxis. Rio de Janeiro, v. 06, n. 10, p. 261-309, 2015.

AUBERT, Isabelle. Droit et liberté. D'un motif récurrent dans la Théorie critique. In: BOCCON-GIBOT, Thomas; GABRIELLI, Caterina (orgs.). Normes, institutions et régulation publique. Editions Hermann, 2015.

AVRITZER, Leonardo. Globalização e espaços públicos: a não regulação como estratégia de hegemonia global. Revista Crítica de Ciências Sociais, n. 63. Coimbra: CES, p. 107-121, 2002.

BRECHT, Bertold. Poemas: 1913-1956. 7. ed. São Paulo: Editora 34, 2012.

CARVALHO, Lidiane E. de. Direito, ambiente e emancipação social. Revista Direito e Práxis. Rio de Janeiro, v. 06, n. 10, p. 645-676, 2015.

HAGINO, Córa H.; QUINTANS, Mariana T. D. O reconhecimento de povos tradicionais e os usos contra-hegemônicos do direito no Brasil: entre a violência e a emancipação social. Revista Direito e Práxis. Rio de Janeiro, v. 06, n. 10, p. 598-644, 2015.

MALDONADO, Fernando G.. Poderá o pluralismo jurídico ser emancipatório? A complexidade do teste de Litmus e da emancipação social em processos de reforma urbana democrática. Revista Direito e Práxis. Rio de Janeiro, v. 06, n. 10, p. 677-703, 2015.

NEUMANN, F. A mudança de função da lei no direito da sociedade burguesa. Revista Brasileira de Estudos Políticos. Belo Horizonte, n. 109, p. 13-87, jul./dez. 2014

OFFE, Claus. The Problem of Social Power in Franz Neumann. Constellations, v. 10, n. 2. Oxford: Blackwell, p. 211-227, 2003.

PEREIRA, Marcus Abílio; CARVALHO, Ernani. Boaventura de Sousa Santos: por uma nova gramática do político e do social. Lua Nova. São Paulo, n. 73, p. 45-58, 2008.

PREUSS, Ulrich K. Formales und Materiales Recht in Franz Neumanns Rechtstheorie. In: ISER, Matthias, STRECKER, David (orgs). Kritische Theorie der Politk. Franz Neumann: ein Bilanz. Baden-Baden: Verlagsgesellschaft, 2002.

RODRIGUEZ, José R. Fuga do Direito: um estudo sobre o direito contemporâneo a partir de Franz Neumann. São Paulo: Editora Saraiva, 2009. 
. Perversão do Direito (e da Democracia): Seis Casos.

Revista Direito e Práxis, v. 7, n. 4, p. 261-295, 2016.

SANTOS. Boaventura de S. Para além do Pensamento Abissal: Das linhas globais a uma ecologia dos saberes. Revista Crítica de Ciências Sociais, n. 78. Coimbra: CES, p. 3-46, 2007a.

Para uma sociologia das ausências e uma sociologia das emergências. Revista Crítica de Ciências Sociais, n. 63. Coimbra: CES, p. 237-280, 2002.

Para um novo senso comum: a ciência, o direito e a política na transição paradigmática. A crítica da razão indolente: contra o desperdício de experiência. 2. ed. São Paulo: Cortez, 2000.

Poderá o direito ser emancipatório?. Revista Crítica de Ciências Sociais, n. 65. Coimbra: CES, p. 3-76, 2003.

Por uma concepção multicultural de direitos humanos. Revista Crítica de Ciências Sociais, n. 48. Coimbra: CES, p. 11-32, 1997.

Renovar a teoria crítica e reinventar a emancipação social. São Paulo: Boitempo, 2007b.

SANTOS, Boaventura de S.; RODRÍGUEZ-GARAVITO, César A. Law, politics, and the subaltern in Counter-hegemonic globalization. In: SANTOS, Boaventura de S.; RODRÍGUEZ-GARAVITO, César

A. (orgs.). Law and globalization from below: towards a cosmopolitan legality. Cambridge: Cambridge University Press, p. 1-26, 2005.

SCHEUERMANN, William. E. Between Norm and Exception: The Frankfurt School and The Rule of Law. Oxford: MIT Press, 1997.

. Franz Neumann: Legal Theorist of Globalization?.

Constellations, v. 8. Oxford: Blackwell, p. 503-520, 2001.

Whistleblowing as Civil Disobedience: The Case of Edward Snowden. Philosophy and Social Criticism, v. 40, n. 7, p. 609-628, 2014.

Recent Theories of Civil Disobedience: An Anti-Legal Turn?. Journal of Political Philosophy, v. 23, n. 4, p. 427-449, 2015. 